\title{
A Review on Determinants of Nutritional Behavior in Teenagers
}

\author{
Morvarid Ghasab Shirazi, ${ }^{1}$ Ashraf Kazemi, ${ }^{2,}$ Roya Kelishadi, ${ }^{3}$ and Firoozeh Mostafavi ${ }^{4}$ \\ ${ }^{1}$ Student Research Committee, School of Nursing and Midwifery, Isfahan University of Medical Sciences, Isfahan, IR Iran \\ ${ }^{2}$ Women's Health Research Center, School of Nursing and Midwifery, Isfahan University of Medical Sciences, Isfahan, IR Iran \\ ${ }^{3}$ Child Growth and Development Research Center, Research Institute for Primordial Prevention of Non Communicable Disease, Isfahan University of Medical Sciences, \\ Isfahan, IR Iran \\ ${ }^{4}$ Department of Health Education and Promotion, School of Public Health, Isfahan University of Medical Sciences, Isfahan, IR Iran \\ "Corresponding author: Ashraf Kazemi, Reproductive Health Department, School of Nursing and Midwifery, Isfahan University of Medical Sciences, Hezarjerib AV., Postal code: \\ 8174673465, Isfahan, IR Iran. Tel: +98-3137927537, Fax: +98-3133868247, E-mail: kazemi@nm.mui.ac.ir
}

Received 2016 April 18; Revised 2017 January 23; Accepted 2017 February 11.

\begin{abstract}
Context: Adolescence is associated with important physical, mental, and social changes leading to rapid changes in behavioral patterns including nutritional behaviors. The nutritional behaviors of individuals as well as changing those behaviors should be recognized to design an effective program. The present study sets to recognize determinants of the adolescents' nutritional behaviors based on the social-ecological model.

Evidence Acquisition: In an extensive literature review, all Farsi and English articles adopted quantitative studies, which were either cross-sectional, longitudinal, or clinical trials. Furthermore, all Farsi and English qualitative studies published from 1990 to 2016 were reviewed. For this purpose, Scopus, Medline, Embase, Cochrane central register of controlled trials and Cochrane database systematic review databases, as well as Farsi databases including Iranmedex, SID, and Magiran were searched. Keywords included nutritional behaviors of teenagers (eating breakfast, fruits, and vegetables, fast foods, unhealthy snacks) and determinant factors. After extracting the effective factors, they were categorized into social-ecological mode.

Results: Since ecological models are focused on individuals' interactions with cultural, environmental, and social factors, applying them to determine the effective factors, and designing interventions based on these factors could enhance the programs for improvement of teenagers' nutritional behaviors.

Conclusions: Changes in intrapersonal and environmental factors could have a more effective role in making changes in teenagers' nutritional behaviors. Since some of these factors become key factors in different social-cultural contexts, nutritional changes in societies have a decisive role in their significance. The significance level of factors and their effect on the target society must be considered for designing more effective interventions.
\end{abstract}

Keywords: Nutritional Behaviors, Teenagers, Ecological Model

\section{Context}

Poor nutrition is a key factor in the spread of noncommunicable diseases around the world (1); and scientific programs based on regional needs are necessary for its improvement. Studies have shown that teenagers are an important group in this programming due to the fact that many unhealthy behaviors in adulthood are shaped during the teenage years (2). Unhealthy nutritional behaviors are important in developing problems such as obesity during this period of life (3) and suffering from serious disorders such as cardiovascular diseases, cancers, stroke, and type 2 diabetes, later in their lives (4). However, extensive global studies have shown that unhealthy nutritional behaviors are more common among this age group $(5,6)$. Previous studies have reported that the most common unhealthy nutritional behaviors among Iranian teenagers are consuming foods containing saturated fats and fried foods, white rice and bread, fatty sweets or salty snacks, as well as insufficient consumption of fruits and vegetables (7-9). Each of these behaviors may endanger individuals' health during pubescence and later in life, and it is necessary to provide programs for preventing them.

For changing, nutritional behaviors of individuals should be recognized to design an effective program (10). Various factors would be effective on different layers and levels of these behaviors (11); hence, having a broad and comprehensive perspective is important in understanding effective factors (4). Ecological models have created a comprehensive approach towards changes in behaviors and decreasing serious and preventable diseases (12). Socialecological perspective has different levels for affecting health behaviors (13), including intrapersonal level, interpersonal level (processes between individual and groups such as family, friends and peers), organizational level (rules and regulations, policies, and unofficial structures), community level (social norms and standards), and public policy level. The present study is set to recognize determinant factors for teenagers' nutritional behaviors based on 
social-ecological model.

\section{Evidence Acquisition}

In an extensive literature review, all Farsi and English articles adopted quantitative studies, either crosssectional, longitudinal, or clinical trials; as well as all Farsi and English qualitative studies published from 1990 to 2016 were reviewed. For this purpose, Scopus, Medline, Embase, Cochrane central register of controlled trials and Cochrane database systematic review databases, as well as Farsi databases including Iranmedex, SID, and Magiran were searched. Keywords included nutritional behaviors of teenagers (eating breakfast, fruits, and vegetables, fast foods, unhealthy snacks) and determinant factors. These keywords were looked up in their pure forms using MeSH, Medical subject headings, and EmTree of scopus. Studies, selected for review having the mentioned keywords, were conducted on the teenage population (10 to 19 years old). Studies, which did not consider nutritional behaviors as well as nutritional behaviors of patients, were excluded from the review. After extracting the effective factors, they were categorized into the social-ecological model (13).

\section{Results}

\subsection{Intrapersonal Determinant Factors of Nutritional Behaviors}

Intrapersonal factors are unique conditions and personal differences that affect individuals' tendency to conduct a behavior. Individuals' perceptions and expectations, derived from experiences through environmental development, create a type of a sensory-affective response for selecting and consuming foods (10).

- Hunger: the physical signal of hunger originates from the stomach and brain. Feeling of hunger as a biologic need is considered the primary determinant for consuming food in teenagers. Eating while one is not hungry (emotional eating) is a common nutritional behavior among teenagers (14). This behavior is an unhealthy nutritional behavior and a factor in obesity (15). Since emotional eating occurs at improper mental conditions such as grieving, loneliness, or anxiety, it could also be an indicator of problems in the teenagers familial relationships (16).

- Gender: lack of nutrients (5) and skipping breakfast as well as lunch $(17,18)$ have been reported more common among teenage girls than boys. However, girls consumed more fruits and vegetable than boys (19). The idea of boys needing more energy exists among teenage boys and girls and this causes boys to have more meals as well as more fatty and energetic foods. Teenage girls mostly focus on their beauty, thus choosing different nutritional behaviors to achieve the goals of slimness and beauty. In fact, gender as a behavior facilitator could affect teenagers' changes in attitude toward formation of a behavior and would lead to nutritional behaviors (20).

- Food preferences: the feeding in infancy provides not only nutritional needs for growth and development, but also an opportunity for learning about foods (21). Learning about foods occurs during the transition from the exclusive breast milk diet of infancy to solid food diet of childhood, which can shape food experiences including the preference for some tastes (22). Food preferences in an individual could also be the result of effects of multiple complicated mental factors including the experience of having a certain food in childhood and negative or positive feeling caused by consuming a certain food (23), or learning (24). Many studies have considered the effect of watching television on formation of food preferences in teenagers; teenagers prefer to have food that is advertised on television (25).

- Awareness: in many studies, although teenagers were completely aware of healthy and unhealthy foods, their nutritional behavior did not match their awareness in practice $(26,27)$. Especially teenage girls, although they had more nutritional awareness than boys, they had more unhealthy nutritional behaviors than boys (26).

- Attitude: attitude through creating behavioral intention leads to formation of nutritional behaviors (28). The value of health for a teenager is directly and indirectly effective on the attitude towards nutrition (29). Furthermore, social-cultural factors, social pressures for being beautiful and skinny in particular, and the attitude of peers and friends are effective on the teenagers' attitude toward nutritional behavior (30); these are in contrast with the value of health.

- Belief and self-efficacy: teenagers' positive belief about nutrition (31) is effective on selecting the type of food and their nutritional behavior by affecting their change of behavior (32). Nutritional self-efficacy, i.e., the individual accepted the ability in choosing the appropriate food, would lead to selection of healthy food, even in facing obstacles (33). Self-efficacy could also be the mediator for parents' support(34) as well as the peers' and friends' support of healthy nutritional behaviors (35).

- Value of health: health concerns would make the necessary motivation for selecting the appropriate food; this motivation has an intermediate effect on determination of attitude toward healthy nutritional behavior. Health concerns, especially meal times with family members, are obvious (36), and they show less concern on not following healthy nutritional behaviors during meals they have with their friends; which is originated from the norms of the friend groups (37). Health concern is not an important de- 
terminant factor for nutritional behavior of teenagers (38) because teenagers are mostly focused on short-term consequences of nutritional behaviors (36). Health concerns increase among teenagers by aging.

- Mental, spiritual, and religious condition: teenagers' mental condition is a risk factor for developing psychological development problems such as antisocial behaviors, suicide, and unhealthy nutritional behaviors (39). Symptoms of depression, especially among teenagers, are associated with food intake (38). Emotional eating (eating in response to negative feelings), is caused by teenagers' lower ability in controlling their emotions or parents' strict control over teenagers' emotions (40). Religious beliefs and convictions of teenagers are also effective on their selection of food (38).

- Accessibility to resources: most teenagers feel that they have limited time, therefore expected time for eating and convenience in consuming the meals (41) are effective in their food selection (36). Teenagers are also sensitive to foods' price, which is also effective on their selection and consumption (42).

- Other behaviors accompanying eating: teenagers spend a lot of time watching television. Studies have shown that while watching television, teenagers tend to drink sweet beverages, omit their meals $(18,43)$, and they usually do not consume fruits and vegetables (44).

\subsection{Interpersonal Determinant Factors of Nutritional Behaviors}

Each person is surrounded by a network of acquaintances in his/her social circle. The network that an individual interacts with during his/her life, determines his/her health behaviors (13).

- Demographic characteristics of family: Parents' educational level is more effective on teenagers' nutritional behaviors than their type of job or income status (45). Mothers' influence is stronger than fathers'; girls with highly educated mothers skip their breakfast less often than others (46), and mother's employment through affecting the availability of food for teenagers affects their choice of foods (47). Family income is also effective on consumption of special food groups such as fruits and vegetables $(48)$ as well as fast foods $(49,50)$. While higher socioeconomic status of families is associated with improvement in the teenager's nutritional behavior (51), there are also some reports regarding the reverse relation between socioeconomic status of family and teenagers' nutritional behaviors in Iran $(7,8,52)$. This controversy indicates that although socioeconomic status provides potential support for healthy nutrition in the family, it leads to behavior modification if accompanied with practical support in providing the nutritional needs of the teenager(19).
- Influence of family members: teenagers' imitation of their same-gender parent regarding nutritional behavior is more i.e., girls imitate their mothers and boys imitate their fathers in healthy and unhealthy nutritional behaviors (16). As teenagers grow older, the effect of parents on their nutritional behaviors changes due to the fact that pubescence is a complicated period of life associated with changes in effects of social factors. Parents' support of healthy eating directly and indirectly, via effecting teenagers' perceptions (35), and nutritional self-efficacy (34), leads to choices of healthy foods.

- Parenting style: A Parenting style is the method of nurturing children. It has two aspects: accepting and controlling (53), and it is divided into 4 categories of authoritarian parenting, authoritative parenting, permissive parenting, and neglecting parenting (54). Since teenagers would like to be independent, authoritative parenting which considers child's needs and rights directly leads teenagers towards choosing healthy foods $(38,55)$. Teenagers' acceptance of their parents' parenting style is also a determinant factor in their nutritional behavior. This acceptance is effective on their self-regulation of eating, meaning that the more they accept their parenting style, the more they regulate themselves (55).

- Availability of food in the family: food style of the family $(5,7)$ is effective on teenagers' nutritional behaviors. Parents could affect teenagers' nutritional behaviors by providing appropriate foods available $(17,56)$. Accessing healthy foods at home would directly determine teenagers' nutritional habit and their type of food intake (44). Socioeconomic status of parents (demographic characteristics of the family) could be effective on teenagers' access to different food types at home. Parents with lower socioeconomic status and lower levels of education would usually prefer foods with higher carbohydrate and fat levels for satisfying the energy need (57); furthermore, the leisure time for these families are usually spent at home watching television without having appropriate physical activities (58), which means access to unhealthy foods and an inactive lifestyle, thus unhealthy nutritional behaviors in their teenagers (59). In fact, watching television by affecting food preferences, teenagers' demand for purchasing the food, and parents' willingness for buying it would affect accessibility to unhealthy foods (25).

- Applying restrictions by parents: applying food restrictions for teenagers would lead to eating without feeling hungry since restrictions are associated with weakened self-control in appetite, decreased trust in satiety signals, and cravings for restricted foods (60). Overweight teenagers have weaker self-control for appetite, and their parents apply more food restrictions on them (61).

- Peers' influence: teenagers spend a lot of time with 
their friends, and eating is an important part of their interactions (62). Exerting pressure by peers' group is the first mechanism for transition of group's norms (63). This would be done through rewarding and reinforcing the behaviors that are in line with the groups' norms (64). Intentional behavior for selecting healthy or unhealthy foods in teenagers could be changed by their friends' encouragement and support (65). Despite teenagers' tendency for independence in their behaviors, imitating the members of peers' group is effective on their choice of foods (66); however, teens are not completely aware of this imitation (62).

- Stresses: stressors for a teenager are usually the environment at home or school, performance at school, or personal problems (67). Individuals' stressors originated from the internal or external environment would disturb their balance and affect individuals' physical and mental condition. When stressed, teenagers consume more calories, snacks (68), fatter foods, and less fruits and vegetables and skip breakfast meals (69). Not everybody reacts to stressors the same way. Teenagers' coping method with stress is a mediator for their nutritional behaviors and mental health. If the teenager is not able to overcome stress, psychological symptoms such as anxiety, unhealthy nutritional behaviors such as overeating become common among them as a result of lack of internal control over stress (incorrect coping) (70).

\subsection{Organizational, Community and Public Policy Determinant Factors of Nutritional Behaviors}

A few studies have evaluated the effective factors on teenagers' nutritional behaviors at higher layers; however, the effect of these layers could not be ignored (71).

- School rules: teenagers spend most of their time at school, so the effect of school environment on their nutritional behavior is crucial (62). Regulations and restriction at school are effective on teenagers' nutritional behaviors $(17,72)$. These rules are mostly effective on preventing the consumption of unhealthy foods than encouraging healthy food intake. Availability of healthy foods at school $(62,73)$ is an important determinant of teenagers' nutritional behaviors; nonetheless, it is not effective on consumption of snacks among teenagers (74). This could be caused by other factors like teenagers' attitude and their interest in food taste.

-Social norms: social norms in a teenager's community (friends and family) could directly affect his/her formation of nutritional behavior (75) or through affecting their behavioral intention indirectly leading to formation of a nutritional behavior (20). Subjective norms, teenagers' perception of actual norms, have a significant predicting role in nutritional behaviors of teenagers. For having an appropriate physical look, teenagers are under social-cultural pressure (76). Having a good physical look is considered more important in girls than boys (77), which is mostly directed toward skinniness and could lead to formation of unhealthy nutritional behaviors (78).

- Food centers: somehow, fast food selling places are considered appropriate for teenagers to spend their time at (62). The number of visits teenagers pay to these places (79) is affected by the so-called conditions. Centers for purchasing foods also determine the food consumption behaviors outside school or home (62). Buying foods from these markets is common among teenagers. These markets are usually close to their school, and their advertisement methods directly affect teenagers in their choice of snacks. Attractive packaging is one of their advertisement methods (26). The distance of these centers from schools is also effective on teenagers' nutritional behaviors (80).

- Media: teenagers are considered the target population of food commercials. They are exposed to different media for food commercials, and these types of media would affect teenagers at home, school, or restaurants (73). Advertising has an important role in the teenagers' nutritional behaviors (81). In fact, exposing teenagers to TV commercials is associated with affording to purchase the food $(32,72)$; the advertised foods are usually fatty and sweet $(82)$ (Figure 1).

\section{Discussion}

Nutrition behaviors formed during the adolescent period are carried into adulthood and, therefore, affect risk for the development of non-communicable disease in later life. Evaluating national programs in Iran has revealed lower effects of nutritional behaviors' changing programs for teenagers than adults (74), due to the changes in food consumption in the Iranian society (83) and inconsistency between interventions and the so-called changes (74). The findings of the study revealed that paying attention to behavior change in individuals may not improve teenagers' nutritional condition, since intrapersonal factors are formed through interactions between individuals and organization. Community and public policy factors play direct and indirect roles in the formation of these relations. Teenagers spend most of their time at school with their friends and peers; also due to their special mental condition, they are influenced by these interactions in their relations with their environment. Therefore changes in intrapersonal and environmental factors could have a more effective role in making changes in the teenagers' nutritional behaviors. Since ecological models are focused on individuals' interactions with cultural, environmental, and social factors (84), applying them to determine the effective factors, and designing interventions based on these 


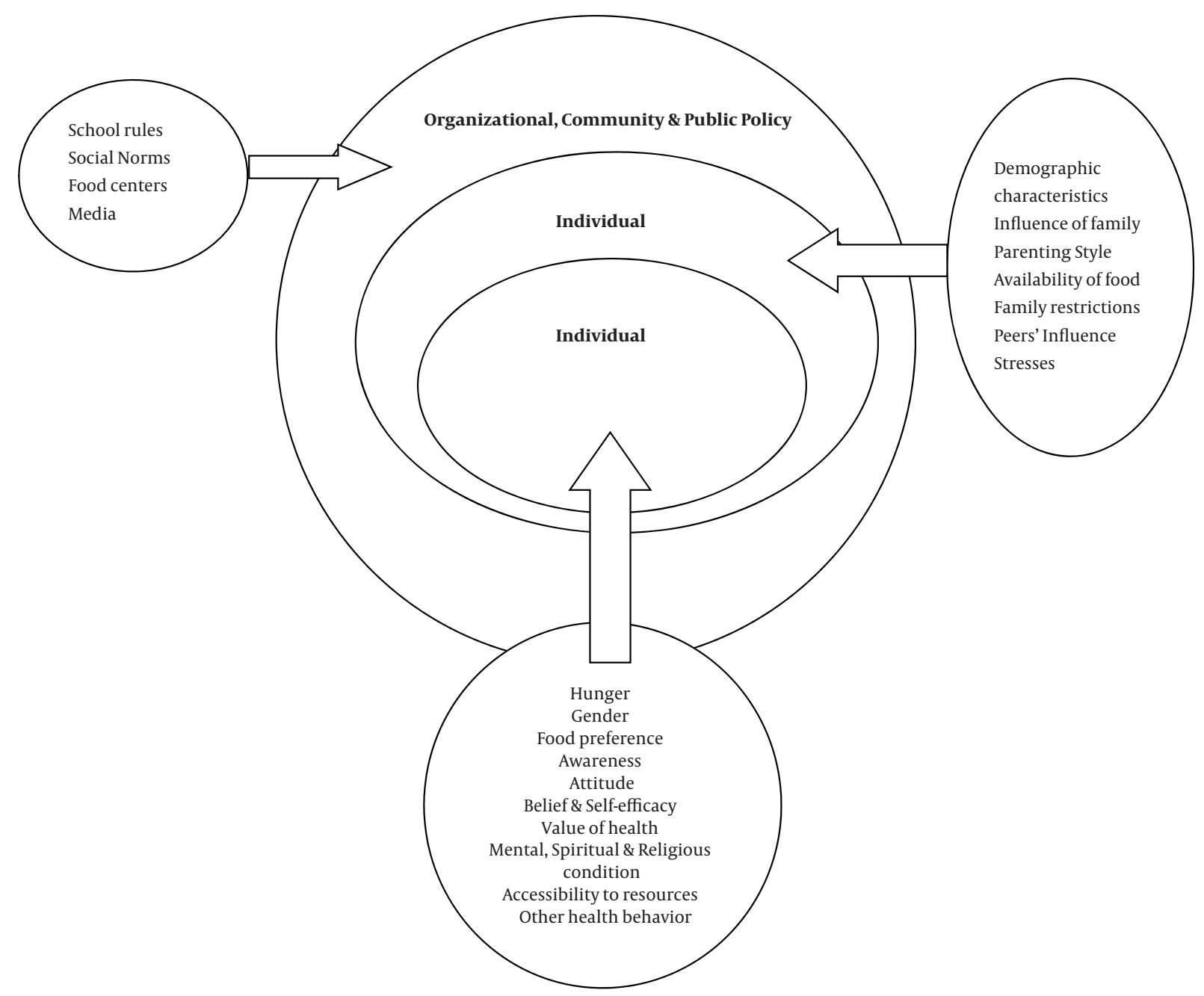

Figure 1. Figure 1

factors could enhance the programs for improvement of teenagers' nutritional behaviors.

\section{Conclusions}

Interventions for changing nutritional behaviors in teenagers should be based on key factors of the target population. In conclusion, from a public health perspective, results of this study have potential implications for interventions designed to make improvement in nutritional behaviors among adolescents. Since some of these determinants become key factors in different social-cultural contexts, nutritional changes in societies have a decisive role in their significance. The significance level of factors and their effect on the target society must be considered for designing more effective interventions.

\section{Footnote}

Funding/Support: This study was supported in part by grant number 394335 from the Isfahan University of Medical Sciences

\section{References}

1. Samuelson G. Global strategy on diet, physical activity and health. Food \& Nutrition Research. 2004;48(2) doi: 10.3402/fnr.v48i2.1503.

2. Gore FM, Bloem PJ, Patton GC, Ferguson J, Joseph V, Coffey C, et al. Global burden of disease in young people aged 10-24 years: a systematic analysis. Lancet. 2011;377(9783):2093-102. doi: 10.1016/S01406736(11)60512-6. [PubMed: 21652063]. 
3. Patrick K, Norman GJ, Calfas KJ, Sallis JF, Zabinski MF, Rupp J, et al. Diet, physical activity, and sedentary behaviors as risk factors for overweight in adolescence. Arch Pediatr Adolesc Med. 2004;158(4):385-90. doi:10.1001/archpedi.158.4.385. [PubMed:15066880].

4. Robinson T. Applying the socio-ecological model to improving fruit and vegetable intake among low-income African Americans. J Community Health. 2008;33(6):395-406. doi: 10.1007/s10900-008-9109-5. [PubMed: 18594953].

5. Larson NI, Neumark-Sztainer D, Hannan PJ, Story M. Trends in adolescent fruit and vegetable consumption, 1999-2004: project EAT. Am J Prev Med. 2007;32(2):147-50. doi: 10.1016/j.amepre.2006.10.011. [PubMed: 17234489].

6. Sjoberg A, Hallberg L, Hoglund D, Hulthen L. Meal pattern, food choice, nutrient intake and lifestyle factors in The Goteborg Adolescence Study. Eur J Clin Nutr. 2003;57(12):1569-78. doi: 10.1038/sj.ejcn.1601726. [PubMed:14647222].

7. Kelishadi R, Ardalan G, Gheiratmand R, Gouya MM, Razaghi EM, Delavari A, et al. Association of physical activity and dietary behaviours in relation to the body mass index in a national sample of Iranian children and adolescents: CASPIAN Study. Bull World Health Organ. 2007;85(1):19-26. [PubMed: 17242754].

8. Mirmiran P, Azadbakht L, Esmaillzadeh A, Azizi F. Dietary diversity score in adolescents - a good indicator of the nutritional adequacy of diets: Tehran lipid and glucose study. Asia Pac J Clin Nutr. 2004;13(1):56-60. [PubMed: 15003915].

9. Salmaani Barough N, Pashaeypour S, Rezaiepour A, Kazemnejad A. Study of quality of snacking in adolescents (12-18 years old). J Hayat. 2007;12(4):21-9.

10. Contento IR. Nutrition education: linking research, theory, and practice. Jones \& Bartlett Learning; 2007.

11. McLeroy KR, Bibeau D, Steckler A, Glanz K. An ecological perspective on health promotion programs. Health Educ Q. 1988;15(4):351-77. [PubMed:3068205].

12. Sallis JF, Owen N, Fisher EB. Ecological models of health behavior Health Behav Health Educ Theory Res Prac. 2008;4:465-86.

13. Glanz K, Rimer BK, Viswanath K. Health behavior and health education: theory, research, and practice. John Wiley \& Sons; 2008.

14. Kral TV, Stunkard AJ, Berkowitz RI, Stallings VA, Brown DD, Faith MS. Daily food intake in relation to dietary energy density in the freeliving environment: a prospective analysis of children born at different risk of obesity. Am J Clin Nutr. 2007;86(1):41-7. [PubMed:17616761].

15. Fisher JO, Birch LL. Eating in the absence of hunger and overweight in girls from 5 to $7 \mathrm{y}$ of age. Am J Clin Nutr. 2002;76(1):226-31. [PubMed: 12081839].

16. de Lauzon-Guillain B, Romon M, Musher-Eizenman D, Heude B, Basdevant A, Charles MA, et al. Cognitive restraint, uncontrolled eating and emotional eating: correlations between parent and adolescent. Matern Child Nutr. 2009;5(2):171-8. doi: 10.1111/j.17408709.2008.00164.x. [PubMed:19292751].

17. Neumark-Sztainer D, Hannan PJ, Story M, Croll J, Perry C. Family meal patterns: associations with sociodemographic characteristics and improved dietary intake among adolescents. J Am Diet Assoc. 2003;103(3):317-22. doi: 10.1053/jada.2003.50048. [PubMed: 12616252].

18. Baygi F, Heshmat R, Kelishadi R, Mohammadi F, Motlagh ME, Ardalan $\mathrm{G}$, et al. Regional Disparities in Sedentary Behaviors and Meal Frequency in Iranian Adolescents: The CASPIAN-III Study. Iran J Pediatr. 2015;25(2):e182. doi: 10.5812/ijp.182. [PubMed: 26195993].

19. Wardle J, Haase AM, Steptoe A, Nillapun M, Jonwutiwes K, Bellisle F. Gender differences in food choice: the contribution of health beliefs and dieting. Ann Behav Med. 2004;27(2):107-16. [PubMed: 15053018].

20. Lien N, Lytle LA, Komro KA. Applying theory of planned behavior to fruit and vegetable consumption of young adolescents. Am J Health Promot. 2002;16(4):189-97. [PubMed:11913324].

21. Liu YH, Stein MT. Feeding behaviour of infants and young children and its impact on child psychosocial and emotional development. In: Tremblay R. E. , Barr R. G. , Peters R. D. V. , editors. Encyclopedia on Early
Childhood Development. ; 2005.

22. Birch L, Savage JS, Ventura A. Influences on the Development of Children's Eating Behaviours: From Infancy to Adolescence. Can J Diet Pract Res. 2007;68(1):s1-s56. [PubMed: 19430591].

23. Birch LL. Development of food preferences. Annu Rev Nutr. 1999;19:4162. doi: 10.1146/annurev.nutr.19.1.41. [PubMed:10448516].

24. Pepino MY, Mennella JA. Factors contributing to individual differences in sucrose preference. Chem Senses. 2005;30 Suppl 1:i319-20. doi: 10.1093/chemse/bjh243. [PubMed: 15738179].

25. Chamberlain LJ, Wang Y, Robinson TN. Does children's screen time predict requests for advertised products? Cross-sectional and prospective analyses. Arch Pediatr Adolesc Med. 2006;160(4):363-8. doi: 10.1001/archpedi.160.4.363. [PubMed:16585480].

26. Mirmiran P, Azadbakht L, Azizi F. Dietary behaviour of Tehranian adolescents does not accord with their nutritional knowledge. Public Health Nutr. 2007;10(9):897-901. doi: 10.1017/S1368980007246701. [PubMed: 17517151].

27. Pirouznia M. The correlation between nutrition knowledge and eating behavior in an American school: the role of ethnicity Nutr Health. 2000;14(2):89-107. doi: 10.1177/026010600001400202. [PubMed: 10904934].

28. Riebl SK, Estabrooks PA, Dunsmore JC, Savla J, Frisard MI, Dietrich AM, et al. A systematic literature review and meta-analysis: The Theory of Planned Behavior's application to understand and predict nutrition-related behaviors in youth. Eat Behav. 2015;18:160-78. doi: 10.1016/j.eatbeh.2015.05.016. [PubMed: 26112228].

29. Sun YH. Health concern, food choice motives, and attitudes toward healthy eating: the mediating role of food choice motives. Appetite 2008;51(1):42-9. doi: 10.1016/j.appet.2007.11.004. [PubMed: 18187232].

30. Fulkerson JA, McGuire MT, Neumark-Sztainer D, Story M, French SA Perry CL. Weight-related attitudes and behaviors of adolescent boys and girls who are encouraged to diet by their mothers. Int J Obes Relat Metab Disord. 2002;26(12):1579-87. doi: 10.1038/sj.ijo.0802157. [PubMed: 12461674].

31. Granner ML, Sargent RG, Calderon KS, Hussey JR, Evans AE, Watkins KW. Factors of fruit and vegetable intake by race, gender, and age among young adolescents. J Nutr Educ Behav. 2004;36(4):173-80. [PubMed: 15544725].

32. Kelly S, Melnyk BM, Belyea M. Predicting physical activity and fruit and vegetable intake in adolescents: a test of the information, motivation, behavioral skills model. Res Nurs Health. 2012;35(2):146-63. doi: 10.1002/nur.21462. [PubMed: 22262049].

33. Lubans DR, Plotnikoff RC, Morgan PJ, Dewar D, Costigan S, Collins CE. Explaining dietary intake in adolescent girls from disadvantaged secondary schools. A test of Social Cognitive Theory. Appetite. 2012;58(2):517-24. doi: 10.1016/j.appet.2011.12.012. [PubMed: 22227067].

34. Young EM, Fors SW, Hayes DM. Associations between perceived parent behaviors and middle school student fruit and vegetable consumption. J Nutr Educ Behav. 2004;36(1):2-8. [PubMed: 14756976].

35. Fitzgerald A, Heary C, Kelly C, Nixon E, Shevlin M. Self-efficacy for healthy eating and peer support for unhealthy eating are associated with adolescents' food intake patterns. Appetite. 2013;63:48-58. doi: 10.1016/j.appet.2012.12.011. [PubMed: 23268111].

36. Askari Majabadi H, Solhi M, Montazeri A, Shojaeizadeh D, Nejat S, Khalajabadi Farahani F, et al. Factors Influencing Fast-Food Consumption Among Adolescents in Tehran: A Qualitative Study. Iran Red Crescent Med J. 2016;18(3):e23890. doi: 10.5812/ircmj.23890. [PubMed: 27247793].

37. Croll JK, Neumark-Sztainer D, Story M. Healthy eating: what does it mean to adolescents?. J Nutr Educ. 2001;33(4):193-8. [PubMed: 11953240].

38. Lytle LA, Varnell S, Murray DM, Story M, Perry C, Birnbaum AS, et al. Predicting adolescents' intake of fruits and vegetables. J Nutr Educ Behav 2003;35(4):170-5. [PubMed: 12859881].

39. Emami H, Ghazinour M, Rezaeishiraz H, Richter J. Mental health of 
adolescents in Tehran, Iran. J Adolesc Health. 2007;41(6):571-6. doi: 10.1016/j.jadohealth.2007.06.005. [PubMed:18023786].

40. van Strien T, Bazelier FG. Perceived parental control of food intake is related to external, restrained and emotional eating in 7-12-year-old boys and girls. Appetite. 2007;49(3):618-25. doi: 10.1016/j.appet.2007.03.227. [PubMed: 17512089].

41. Neumark-Sztainer D, Story M, Perry C, Casey MA. Factors influencing food choices of adolescents: findings from focus-group discussions with adolescents. J Am Diet Assoc. 1999;99(8):929-37. doi: 10.1016/S0002-8223(99)00222-9. [PubMed: 10450307].

42. French SA, Jeffery RW, Story M, Breitlow KK, Baxter JS, Hannan P, et al. Pricing and promotion effects on low-fat vending snack purchases: the CHIPS Study. Am J Public Health. 2001;91(1):112-7. [PubMed: 11189801].

43. de Bruijn GJ, van den Putte B. Adolescent soft drink consumption, television viewing and habit strength. Investigating clustering effects in the Theory of Planned Behaviour. Appetite. 2009;53(1):66-75. doi:10.1016/j.appet.2009.05.008. [PubMed:19463873].

44. Haerens L, Craeynest M, Deforche B, Maes L, Cardon G, De Bourdeaudhuij I. The contribution of psychosocial and home environmental factors in explaining eating behaviours in adolescents. Eur J Clin Nutr. 2008;62(1):51-9. doi: 10.1038/sj.ejcn.1602681. [PubMed: 17299461].

45. Goodwin DK, Knol LL, Eddy JM, Fitzhugh EC, Kendrick OW, Donahue RE. The relationship between self-rated health status and the overall quality of dietary intake of US adolescents. J Am Diet Assoc. 2006;106(9):1450-3. doi: 10.1016/j.jada.2006.06.011. [PubMed: 16963351].

46. Hallstrom L, Vereecken CA, Ruiz JR, Patterson E, Gilbert CC, Catasta G, et al. Breakfast habits and factors influencing food choices at breakfast in relation to socio-demographic and family factors among European adolescents. The HELENA Study. Appetite. 2011;56(3):649-57. doi: 10.1016/j.appet.2011.02.019. [PubMed: 21376767]

47. Bowers D. Cooking trends echo changing roles of women. Food Rev Magazine Food Econ. 2000;23(1)

48. Lowry R, Kann L, Collins JL, Kolbe LJ. The effect of socioeconomic status on chronic disease risk behaviors among US adolescents. JAMA. 1996;276(10):792-7. [PubMed: 8769588].

49. Ghafari M, Ebadi L, Ramazankhani A, Souri H. Fast food consumption and its related factors among students: A cross-sectional study. Majalleh Tahqiqate Nezame Salamat. 2012;8(6):981-90.

50. Yarmohammadi P, Sharifirad GR, Azadbakht L, Morovati SMA, Hassanzadeh A. Predictors of fast food consumption among high school students based on the theory of planned behavior. J Uni Gorgan Med Sci. 2011;7(4):449-59.

51. Duckworth AL, Tsukayama E, Geier AB. Self-controlled children stay leaner in the transition to adolescence. Appetite. 2010;54(2):304-8. doi: 10.1016/j.appet.2009.11.016. [PubMed: 20004223].

52. Arshi S, Ghanbari B, Nemati K, Soleiman EY, Torkaman NS, Kolahi AA. Nutritional Behaviors Pattern of High School Girls in North of Tehran. Commun Health. 2015;1(2):99-110.

53. Baumrind D. The Influence of Parenting Style on Adolescent Competence and Substance Use. J Early Adolesc. 1991;11(1):56-95. doi: 10.1177/0272431691111004.

54. Patock-Peckham JA, Cheong J, Balhorn ME, Nagoshi CT. A social learning perspective: a model of parenting styles, self-regulation, perceived drinking control, and alcohol use and problems. Alcohol Clin Exp Res. 2001;25(9):1284-92. [PubMed: 11584147].

55. van der Horst K, Kremers S, Ferreira I, Singh A, Oenema A, Brug J. Perceived parenting style and practices and the consumption of sugarsweetened beverages by adolescents. Health Educ Res. 2007;22(2):295304. doi: 10.1093/her/cylo80. [PubMed: 16908496].

56. Larson NI, Story M, Wall M, Neumark-Sztainer D. Calcium and dairy intakes of adolescents are associated with their home environment, taste preferences, personal health beliefs, and meal patterns. JAm Diet Assoc. 2006;106(11):1816-24. doi: 10.1016/j.jada.2006.08.018. [PubMed: 17081833].
57. Finger JD, Tylleskar T, Lampert T, Mensink GB. Dietary behaviour and socioeconomic position: the role of physical activity patterns. PLoS One. 2013;8(11):e78390. doi: 10.1371/journal.pone.0078390. [PubMed: 24223150].

58. Finger JD, Tylleskar T, Lampert T, Mensink GB. Physical activity patterns and socioeconomic position: the German National Health Interview and Examination Survey 1998 (GNHIES98). BMC Public Health. 2012;12:1079. doi: 10.1186/1471-2458-12-1079. [PubMed: 23241280].

59. Ranjit N, Evans MH, Byrd-Williams C, Evans AE, Hoelscher DM. Dietary and activity correlates of sugar-sweetened beverage consumption among adolescents. Pediatrics. 2010;126(4):e754-61. doi: 10.1542/peds.2010-1229. [PubMed: 20876172].

60. Birch LL, Fisher JO. Development of eating behaviors among children and adolescents. Pediatrics. 1998;101(3 Pt 2):539-49. [PubMed: $12224660]$.

61. Keller KL, Pietrobelli A, Johnson SL, Faith MS. Maternal restriction of children's eating and encouragements to eat as the 'non-shared environment': a pilot study using the child feeding questionnaire. Int J Obes (Lond). 2006;30(11):1670-5. doi: 10.1038/sj.ijo.0803318. [PubMed: 16568136]

62. Story M, Neumark-Sztainer D, French S. Individual and environmental influences on adolescent eating behaviors. J Am Diet Assoc. 2002;102(3 Suppl):S40-51. [PubMed: 11902388].

63. Lieberman M, Gauvin L, Bukowski WM, White DR. Interpersonal influence and disordered eating behaviors in adolescent girls: the role of peer modeling, social reinforcement, and body-related teasing. Eat Behav. 2001;2(3):215-36. [PubMed:15001032].

64. Brown BB. The role of peer groups in adolescents' adjustment to secondary school. London: John Wiley \& Sons; 1989.

65. Stok FM, de Vet E, de Ridder DT, de Wit JB. The potential of peer social norms to shape food intake in adolescents and young adults: a systematic review of effects and moderators. Health Psychol Rev. 2016;10(3):326-40. doi: 10.1080/17437199.2016.1155161. [PubMed: 26878931].

66. Romero ND, Epstein LH, Salvy SJ. Peer modeling influences girls' snack intake. J Am Diet Assoc. 2009;109(1):133-6. doi: 10.1016/j.jada.2008.10.005. [PubMed: 19103334].

67. Son S, Ro Y, Hyun H, Lee H, Song K. A comparative study on dietary behavior, nutritional knowledge and life stress between Korean and Chinese female high school students. Nutr Res Pract. 2014;8(2):205-12. doi: 10.4162/nrp.2014.8.2.205. [PubMed: 24741406].

68. Roemmich JN, Wright SM, Epstein LH. Dietary restraint and stress-induced snacking in youth. Obes Res. 2002;10(11):1120-6. doi: 10.1038/oby.2002.152. [PubMed: 12429875].

69. Cartwright M, Wardle J, Steggles N, Simon AE, Croker H, Jarvis MJ. Stress and dietary practices in adolescents. Health Psychol. 2003;22(4):362-9. [PubMed: 12940392].

70. Ahn Y, Kim H, Kim K. A study on weight control, nutritional knowledge, dietary attitudes and eating behaviors among high school female students. Korean J Commun Nutr. 2006;11(2):205-17.

71. de Vet E, de Ridder DT, de Wit JB. Environmental correlates of physical activity and dietary behaviours among young people: a systematic review of reviews. Obes Rev. 2011;12(5):e130-42. doi: 10.1111/j.1467789X.2010.00784.x. [PubMed: 20630024].

72. Maddah M, Rashidi A, Mohammadpour B, Vafa R, Karandish M. Inschool snacking, breakfast consumption, and sleeping patterns of normal and overweight Iranian high school girls: a study in urban and rural areas in Guilan, Iran.J Nutr Educ Behav. 2009;41(1):27-31. doi: 10.1016/j.jneb.2008.03.115. [PubMed: 19161917].

73. Centers for Disease Control Prevention . School health guidelines to promote healthy eating and physical activity. MMWR. Recommendations and reports: Morbidity and mortality weekly report. Recommendations and reports. ; 2011 .

74. Mohammadifard N, Sarrafzadegan N, Ghassemi GR, Nouri F, Pashmi R. Alteration in unhealthy nutrition behaviors in adolescents 
through community intervention: Isfahan Healthy Heart Program. ARYA Atheroscler. 2013;9(1):89-97. [PubMed: 23696765].

75. Lally P, Bartle N, Wardle J. Social norms and diet in adolescents. Appetite. 2011;57(3):623-7. doi: 10.1016/j.appet.2011.07.015. [PubMed: 21843568].

76. Reina SA, Shomaker LB, Mooreville M, Courville AB, Brady SM, Olsen $C$, et al. Sociocultural pressures and adolescent eating in the absence of hunger. Body Image. 2013;10(2):182-90. doi: 10.1016/j.bodyim.2012.12.004. [PubMed: 23394966].

77. Moore DC. Body image and eating behavior in adolescents. J Am Coll Nutr. 1993;12(5):505-10. [PubMed: 8263264].

78. McKnight I. Risk factors for the onset of eating disorders in adolescent girls: results of the McKnight longitudinal risk factor study. $A m$ J Psychiatry. 2003;160(2):248-54. doi: 10.1176/ajp.160.2.248. [PubMed: 12562570].

79. Lin BH, Guthrie J, Frazao E. Nutrient contribution of food away from home. America's eat habits: Changes Consequences. ; 1999.
80. Davis B, Carpenter C. Proximity of fast-food restaurants to schools and adolescent obesity. Am J Public Health. 2009;99(3):505-10. doi: 10.2105/AJPH.2008.137638. [PubMed: 19106421].

81. American Academy of Pediatrics. Committee on Public E. American Academy of Pediatrics: Children, adolescents, and television. Pediatrics. 2001;107(2):423-6. [PubMed: 11158483].

82. Kelishadi R, Ardalan G, Gheiratmand R, Sheikholeslam R, Majdzadeh SR, Delavari AR, et al. Do the dietary habits of our community warrant health of children and adolescents now and in future? CASPIAN Study. Iran J Pediatr. 2005;15(2):97-109.

83. Ghassemi H, Harrison G, Mohammad K. An accelerated nutrition transition in Iran. Public Health Nutr. 2002;5(1A):149-55. doi: 10.1079/PHN2001287. [PubMed: 12027278].

84. Stokols D. Translating social ecological theory into guidelines for community health promotion. Am J Health Promot. 1996;10(4):282-98. [PubMed: 10159709]. 